\title{
Post-training intrahippocampal inhibition of class I histone deacetylases enhances long-term object-location memory
}

\author{
Joshua D. Hawk, ${ }^{1,2}$ Cédrick Florian, ${ }^{2}$ and Ted Abel ${ }^{2,3}$ \\ ${ }^{1}$ Neuroscience Graduate Group, University of Pennsylvania, Philadelphia, Pennsylvania 19104, USA; ${ }^{2}$ Department of Biology, \\ University of Pennsylvania, Philadelphia, Pennsylvania 19104, USA
}

\begin{abstract}
Long-term memory formation involves covalent modification of the histone proteins that package DNA. Reducing histone acetylation by mutating histone acetyltransferases impairs long-term memory, and enhancing histone acetylation by inhibiting histone deacetylases (HDACs) improves long-term memory. Previous studies using HDAC inhibitors to enhance longterm memory have focused on the fear-conditioning task using broad-spectrum HDAC inhibitors. We have found that post-training intrahippocampal administration of the broad-spectrum HDAC inhibitor trichostatin A (TSA) or the class I HDAC-selective inhibitor MS275 enhances long-term object-location memory, supporting a role for class I HDACs in the enhancement of hippocampus-dependent memory induced by HDAC inhibition.
\end{abstract}

The formation of a long-term memory requires de novo gene transcription in the hours following learning (Hawk and Abel 2010). Covalent modifications, such as acetylation, occur on the histone proteins that package genes to guide transcription (Jenuwein and Allis 2001). It has become clear that histone acetylation contributes to memory formation (Wood et al. 2006b; Barrett and Wood 2008; Sweatt 2009; Morris et al. 2010). Histone acetylation increases after learning (Levenson et al. 2004; Chwang et al. 2006; Bredy et al. 2007; Peleg et al. 2010), and the histone acetyltransferase CREB-binding protein (CBP) is critical for memory storage (Oike et al. 1999; Alarcon et al. 2004; Korzus et al. 2004; Wood et al. 2005, 2006a). Specific point mutations in CBP that block the recruitment of CBP to CREB (Wood et al. 2006a) or that eliminate the histone acetyltransferase activity of CBP (Korzus et al. 2004) selectively impair long-term memory. Also, the contextual fear memory deficit observed in mice lacking one copy of CBP is ameliorated by pharmacologically inhibiting the histone deacetylases (HDACs) that oppose CBP (Alarcon et al. 2004), presumably through enhancing the efficacy of histone acetylation by the CBP that remains.

Treatment of rodents with inhibitors of HDACs enhances long-term memory (Alarcon et al. 2004; Korzus et al. 2004; Levenson et al. 2004; Yeh et al. 2004; Lattal et al. 2007; Vecsey et al. 2007; Bredy and Barad 2008; Guan et al. 2009; Stefanko et al. 2009; Peleg et al. 2010; Roozendaal et al. 2010). Most previous studies examined the hippocampus-dependent contextual fear-conditioning task (Alarcon et al. 2004; Levenson et al. 2004; Vecsey et al. 2007; Guan et al. 2009; Peleg et al. 2010) or extinction of fear memory (Lattal et al. 2007; Bredy and Barad 2008). Recently, memory enhancement by HDAC inhibitor treatment was observed for object-recognition memory (Stefanko et al. 2009) and object-location memory (Haettig et al. 2011). In contrast to object-location memory (Haettig et al. 2011) and contextual fear conditioning (Vecsey et al. 2007), the effect of HDAC inhibition on object-recognition memory does not require the CREB-CBP interaction (Stefanko et al. 2009). This mechanistic

${ }^{3}$ Corresponding author.

E-mail abele@sas.upenn.edu; fax (215) 898-8780.

Article is online at http://www.learnmem.org/cgi/doi/10.1101//m.2097411. distinction is supported by an anatomical dissociation in the effect of HDAC inhibitors on different forms of object-based memory (Roozendaal et al. 2010). Injection of the HDAC inhibitor sodium butyrate into the insular cortex of rats enhances object-recognition memory without affecting object-location memory, whereas sodium butyrate administration into the hippocampus enhances object-location memory without impacting object-recognition memory (Roozendaal et al. 2010). These findings are consistent with our recent observation that the hippocampus is required for object-location memory, but not for object-recognition memory (Oliveira et al. 2010) and suggest that the object-location memory task may be a useful tool to examine the mechanisms of enhancement in hippocampusdependent memory by HDAC inhibitors.

HDAC inhibitors used for the study of memory typically act on both class I and class II HDACs. For instance, trichostatin A (TSA) and suberoylanilide hydroxamic acid (SAHA) inhibit a variety of class I and class II HDACs with similar efficacy (Wu et al. 2004; Khan et al. 2008). Yet, recent experiments suggest that HDAC2, a class I HDAC, may be the functionally relevant target of HDAC inhibitors involved in memory enhancement (Guan et al. 2009). Also, the common target of HDAC inhibitors that improve memory in an Alzheimer's mouse model appears to be class I HDACs (Kilgore et al. 2010). These results suggest that a class I-selective HDAC inhibitor may be as efficacious for memory enhancement as drugs that target both class I and II HDACs. MS275 is a potent and selective class I HDAC inhibitor (Suzuki et al. 1999; Simonini et al. 2006; Beckers et al. 2007; Khan et al. 2008) that has been found to alter depressive-like behavior mediated by HDAC2 (Covington et al. 2009), but it is not known whether this compound is effective at enhancing long-term memory.

In the present study, we first sought to establish whether HDAC inhibition enhances long-term object-location memory in mice using the HDAC inhibitor TSA. HDAC inhibitor or vehicle was delivered to the dorsal hippocampus of male C57BL/6J mice through guide cannulae (Fig. 1A) as described previously (Vecsey et al. 2007; Oliveira et al. 2010). Administration of TSA by this method increases histone acetylation in the hippocampus within $30 \mathrm{~min}$ of administration with acetylation returning to 
A

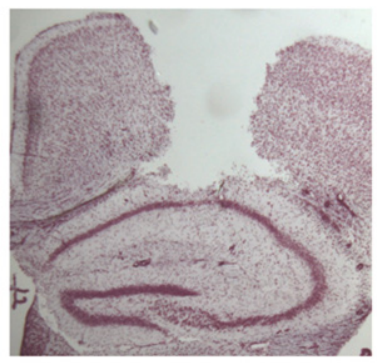

B

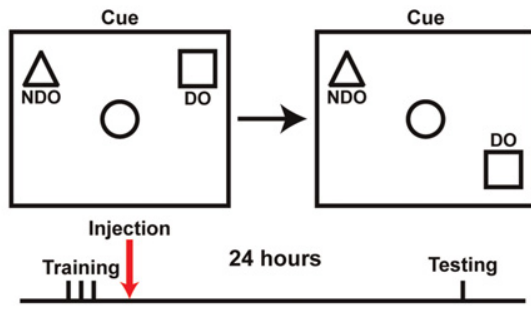

C

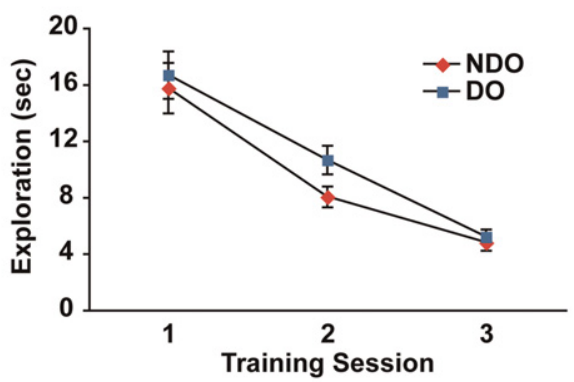

D

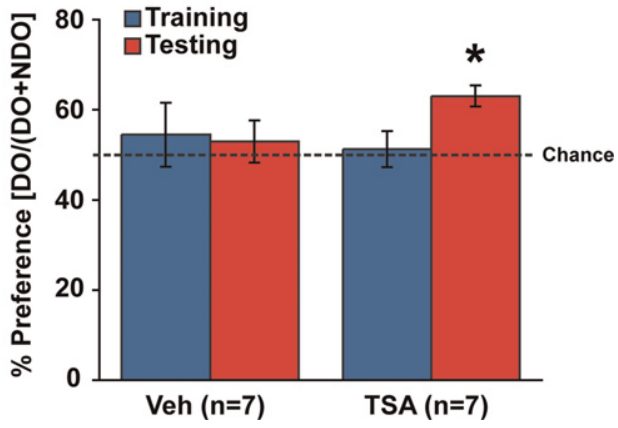

Figure 1. Post-training intrahippocampal injection of the class I and class II HDAC inhibitor TSA enhances long-term object-location memory. (A) Illustration of cannula placement in the dorsal hippocampus. Mice were allowed to recover for $1 \mathrm{wk}$ after cannula implantation. Coronal brain slices were stained with cresyl violet. (B) Schematic diagram illustrating the object-location memory task during training (left) and testing (right). A visual cue was attached to one wall ("cue"). After the third training session, mice were injected with $0.5 \mu \mathrm{L}$ of TSA $(16.5 \mathrm{mM})$ or vehicle $(50 \%$ Ethanol) per hippocampus. Testing was performed $24 \mathrm{~h}$ after training. (C) During the three training sessions, exploration time gradually decreased $(P<0.001)$ for both the object to be displaced (DO) and the nondisplaced object (NDO). No difference was observed between exploration time for the DO and NDO $(P=0.223)$. (D) Mice injected with TSA showed increase preference for the $\mathrm{DO}$ during the testing session relative to the last training session $(P=0.017)$, whereas vehicle-injected mice did not $(P=0.886)$. Equivalent exploration of both objects is indicated with a dashed line at $50 \%$ ("chance"). Error bars represent SEM.

basal levels within $24 \mathrm{~h}$ of injection (Vecsey et al. 2007). When administered immediately after fear conditioning, TSA selectively enhances long-term contextual fear memory (Vecsey et al. 2007). Using the same method of post-training intrahippocampal delivery for the GABA receptor type A agonist muscimol, reversible inactivation of the hippocampus prevents memory formation in the object-location memory task (Oliveira et al. 2010).

The hippocampus-dependent object-location memory task exploits the observation that mice explore objects more when the position of the object is changed relative to previous experiences (Save et al. 1992). Training and testing in this task were performed as previously described (Oliveira et al. 2010). Mice were handled in the experimental room for $1 \mathrm{~min}$ per day for $3 \mathrm{~d}$ prior to training. On the day of training, mice were placed into the training arena for a total of four 6-min sessions with an intersession interval of $3 \mathrm{~min}$ in the home cage. The first session consisted of a context habituation period without objects in the arena. In the next three sessions, mice were placed in the training arena with three distinct objects (Fig. 1B). The middle object was used as a reference object only, as exploration of the object in the center of the arena was reduced in comparison to the symmetrically placed outer objects (data not shown). Over the course of the three training sessions, object exploration time gradually decreased $\left(F_{(2,23)}=50.4, P<0.001\right)$. Object exploration times in training sessions 1,2 , and 3 were $32.4 \pm 2.9 \mathrm{sec}, 18.6 \pm 1.5 \mathrm{sec}$, and $10.0 \pm 0.8 \mathrm{sec}$, respectively, suggesting that mice acquired information about the objects.

Immediately after the last training session, TSA or vehicle was delivered bilaterally to the hippocampi (Fig. 1B). No difference was observed in exploration time during training between mice that would ultimately be treated with TSA or vehicle $\left(F_{(1,24)}=2.105, P=0.160\right)$. Twenty-four hours after training, the mice were reintroduced to the training arena with the displaced object (DO) moved to a new location, whereas a symmetrically positioned nondisplaced object (NDO) was not moved (Fig. 1B). No difference in exploration time was observed during training between the objects that would ultimately be the DO and the NDO (Fig. $1 C ; F_{(1,24)}=1.50, P=0.233$ ). Exploration times during the final training session were: vehicle-NDO $4.62 \pm 0.83$, vehicleDO $5.40 \pm 0.87$, TSA-NDO $4.93 \pm 0.80$, and TSA-DO $4.97 \pm 0.53$ (in seconds \pm SEM). Preference for the DO was calculated as the percentage of object exploration time dedicated to this object $(100 \% \times \mathrm{DO} /(\mathrm{DO}+\mathrm{NDO}))$. During training, preferences for the future DO were at approximately chance levels (Fig. ID). During the 24-hour test of long-term object-location memory, TSAtreated mice showed a significant increase in preference for the DO relative to the final training session (paired samples $t$-test, $P=0.017)$. In contrast, mice treated with vehicle did not show increased preference for the DO (paired samples $t$-test, $P=0.886$ ). Exploration times during the testing session were: vehicle-NDO $7.23 \pm 0.75$, vehicle-DO $8.36 \pm 0.97$, TSA-NDO $6.64 \pm 0.94$, and TSA-DO $11.29 \pm 1.27$ (in seconds \pm SEM). Because HDAC inhibitors were injected after training, these data are in agreement with previous observations that HDAC inhibitors enhance the consolidation of hippocampus-dependent memory (Vecsey et al. 2007). Further, these data are consistent with a role of the hippocampus in object-location memory (Oliveira et al. 2010) and the ability of HDAC inhibitors to enhance performance in this task for rats (Roozendaal et al. 2010).

We next tested the ability of the class I-selective inhibitor MS275 to improve long-term memory in the object-location memory test (Fig. 2). Training and injection protocols were identical to those described for TSA, except that MS275 and the appropriate vehicle were infused after training. Intrahippocampal administration of MS275 has been previously observed to increase histone H3 acetylation after contextual learning (Peleg et al. 2010). Object exploration time gradually decreased with training sessions $\left(F_{(2,27)}=37.175, P<0.001\right)$. For training sessions 1,2 , and 3 , total object exploration times for the training sessions were $24.4 \pm 1.7 \mathrm{sec}, 18.7 \pm 1.6 \mathrm{sec}$, and $11.2 \pm 1.2 \mathrm{sec}$, respectively. 

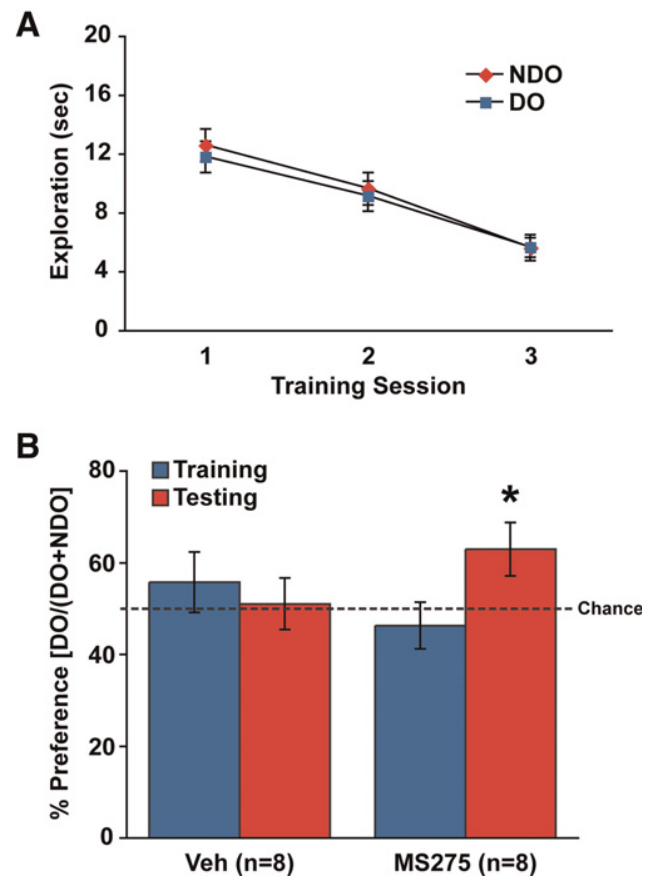

Figure 2. Post-training intrahippocampal injection of the class I-selective HDAC inhibitor MS275 enhances long-term object-location memory. (A) During the three training sessions, exploration of the displaced object (DO) and the nondisplaced object (NDO) decreased $(P<0.001)$. No difference was observed in exploration time between the DO and the NDO $(P=0.647)$. (B) Preference for the DO increased in mice injected with MS275 (1 mM in 1\% DMSO) during the testing session relative to the last training session $(P=0.019)$, whereas no increase in preference was observed in vehicle-injected mice $(P=0.539)$. Equivalent exploration of both objects is indicated with a dashed line at 50\% ("chance"). Error bars represent SEM.

Exploration times during the final training session were: vehicleNDO $4.31 \pm 0.63$, vehicle-DO $5.78 \pm 1.00$, MS275-NDO $6.92 \pm$ 1.49 , and MS275-DO $5.46 \pm 0.86$ (in seconds \pm SEM). No difference was observed during training between mice that would ultimately be treated with MS275 or vehicle $\left(F_{(1,28)}=0.60, P=\right.$ $0.445)$, nor was a difference observed during training between the objects that would ultimately be the DO and the NDO (Fig. $\left.2 \mathrm{~A} ; F_{(1,28)}=0.214, P=0.647\right)$. Consistent with this observation, the percent preference for the DO was $\sim 50 \%$ during training (Fig. 2B). Testing with one object displaced at $24 \mathrm{~h}$ after training showed that the preference for the DO increases in MS275-treated mice relative to the last training session (paired samples $t$-test, $P=0.019$ ). Vehicle-injected mice did not show any change in preference for the DO (paired samples $t$-test, $P=$ 0.539). Exploration times during the testing session were: vehicle-NDO $5.45 \pm 0.93$, vehicle-DO $5.39 \pm 0.83$, MS275-NDO $5.40 \pm 1.09$, and MS275-DO $8.30 \pm 0.76$ (in seconds \pm SEM). Thus, our data suggest that MS275, like TSA, is able to enhance long-term memory for the location of objects. The injection of HDAC inhibitors after acquisition and the lack of a direct biochemical effect on histone acetylation at $24 \mathrm{~h}$ after injection (Vecsey et al. 2007) together suggest that the observed increase in memory is likely mediated by improved consolidation. To our knowledge, these data are the first to show that treatment with a class I-selective HDAC inhibitor enhances hippocampusdependent memory.

HDAC inhibitors can cause a variety of undesirable side effects (Prince et al. 2009), so identifying the most selective inhibitor capable of improving cognitive function is an important goal.
Here, we show that inhibition of class I HDACs using MS275 facilitates long-term memory performance in a hippocampus-dependent object-location memory task. Class I HDACs include HDAC1, HDAC2, HDAC3, and HDAC8, but MS275 shows a preference for HDAC1 and HDAC2 relative to HDAC3 and does not appreciably inhibit HDAC8 (Hu et al. 2003; Vannini et al. 2004; Inoue et al. 2006), suggesting that either HDAC1 or HDAC2 is the critical target of MS275 for memory enhancement. Expression of HDAC1 is highest in neuronal precursors and glia, but HDAC2 is expressed heavily in mature neurons (MacDonald and Roskams 2008). Transgenic expression of mutant forms of the histone acetyltransferase CBP selectively in neurons causes long-term memory deficits (Korzus et al. 2004; Wood et al. 2005). Similarly, overexpression of HDAC2 in neurons causes memory impairments, whereas neuronal overexpression of HDAC1 does not impact memory formation (Guan et al. 2009). Yet, conditional deletion of HDAC3 in the dorsal hippocampus enhances long-term memory (McQuown et al. 2011), suggesting that both HDAC2 and HDAC3 may contribute to memory formation. Our findings are consistent with genetic studies suggesting that neuronal HDAC2 may be a key target of HDAC inhibitor activity to enhance longterm memory, but it is important to note that a contribution of HDAC1 or HDAC3 cannot be excluded by the present study.

Neuropsychiatric disorders such as depression and schizophrenia are accompanied by impaired cognitive function. Histone deacetylase inhibitors are a promising class of drugs for the amelioration of cognitive deficits in these disorders. Previous studies in rats found that long-term object-location memory is enhanced by intrahippocampal injection of sodium butyrate (Roozendaal et al. 2010), but this is the first study to demonstrate that HDAC inhibitors enhance this form of memory in mice. Because peripheral MS275 administration has been reported to increase hippocampal histone acetylation (Simonini et al. 2006), it will be an intriguing future direction to determine whether peripheral administration of MS275 improves hippocampusdependent memory, as we observed with intrahippocampal administration. The use of mice in these studies is important because pharmacological and genetic approaches can be combined in mice to define the precise molecular mechanisms that underlie the enhancement in hippocampus-dependent memory by HDAC inhibitors. Using such a combined approach is likely to yield insight into the processes targeted by HDACs to enhance memory, a goal that will be important for the development of a truly selective pharmacological strategy to enhance cognitive performance.

\section{Acknowledgments}

We thank Shane Poplawski, Mathieu Wimmer, and Robbert Havekes for comments on the manuscript and experimental design. This work was funded by NIH R01 MH060244 to T.A. Further funding from NIH Predoctoral Training Program in Genetics (T32-GM-008216-20) provided support to J.D.H.

\section{References}

Alarcon JM, Malleret G, Touzani K, Vronskaya S, Ishii S, Kandel ER, Barco A. 2004. Chromatin acetylation, memory, and LTP are impaired in $\mathrm{CBP}+$ / - mice: A model for the cognitive deficit in Rubinstein-Taybi syndrome and its amelioration. Neuron 42: 947-959.

Barrett RM, Wood MA. 2008. Beyond transcription factors: The role of chromatin modifying enzymes in regulating transcription required for memory. Learn Mem 15: 460-467.

Beckers T, Burkhardt C, Wieland H, Gimmnich P, Ciossek T, Maier T, Sanders K. 2007. Distinct pharmacological properties of second generation HDAC inhibitors with the benzamide or hydroxamate head group. Int J Cancer 121: $1138-1148$.

Bredy TW, Barad M. 2008. The histone deacetylase inhibitor valproic acid enhances acquisition, extinction, and reconsolidation of conditioned fear. Learn Mem 15: 39-45. 
Bredy TW, Wu H, Crego C, Zellhoefer J, Sun YE, Barad M. 2007. Histone modifications around individual BDNF gene promoters in prefrontal cortex are associated with extinction of conditioned fear. Learn Mem 14: $268-276$.

Chwang WB, O'Riordan KJ, Levenson JM, Sweatt JD. 2006. ERK/MAPK regulates hippocampal histone phosphorylation following contextual fear conditioning. Learn Mem 13: 322-328.

Covington HE, 3rd, Maze I, LaPlant QC, Vialou VF, Ohnishi YN, Berton O, Fass DM, Renthal W, Rush AJ, 3rd, Wu EY, et al. 2009. Antidepressant actions of histone deacetylase inhibitors. J Neurosci 29: 11451-11460.

Guan JS, Haggarty SJ, Giacometti E, Dannenberg JH, Joseph N, Gao J, Nieland TJ, Zhou Y, Wang X, Mazitschek R, et al. 2009. HDAC2 negatively regulates memory formation and synaptic plasticity. Nature 459: $55-60$.

Haettig J, Stefanko DP, Multani ML, Figueroa DX, McQuown SC, Wood MA. 2011. HDAC inhibition modulates hippocampus-dependent long-term memory for object location in a CBP-dependent manner. Learn Mem 18: $71-79$.

Hawk JD, Abel T. 2010. Role of gene transcription in long-term memory storage. In Encyclopedia of behavioral neuroscience (ed. GF Koob), Vol 3, pp. 161-179. Academic Press, Oxford, UK.

Hu E, Dul E, Sung CM, Chen Z, Kirkpatrick R, Zhang GF, Johanson K, Liu R, Lago A, Hofmann G, et al. 2003. Identification of novel isoformselective inhibitors within class I histone deacetylases. J Pharmacol Exp Ther 307: 720-728.

Inoue S, Mai A, Dyer MJ, Cohen GM. 2006. Inhibition of histone deacetylase class I but not class II is critical for the sensitization of leukemic cells to tumor necrosis factor-related apoptosis-inducing ligand-induced apoptosis. Cancer Res 66: 6785-6792.

Jenuwein T, Allis CD. 2001. Translating the histone code. Science 293: 1074-1080.

Khan N, Jeffers M, Kumar S, Hackett C, Boldog F, Khramtsov N, Qian X, Mills E, Berghs SC, Carey N, et al. 2008. Determination of the class and isoform selectivity of small-molecule histone deacetylase inhibitors. Biochem J 409: 581-589.

Kilgore M, Miller CA, Fass DM, Hennig KM, Haggarty SJ, Sweatt JD, Rumbaugh G. 2010. Inhibitors of class 1 histone deacetylases reverse contextual memory deficits in a mouse model of Alzheimer's disease. Neuropsychopharmacology 35: 870-880.

Korzus E, Rosenfeld MG, Mayford M. 2004. CBP Histone acetyltransferase activity is a critical component of memory consolidation. Neuron 42: 961-972.

Lattal KM, Barrett RM, Wood MA. 2007. Systemic or intrahippocampal delivery of histone deacetylase inhibitors facilitates fear extinction. Behav Neurosci 121: 1125-1131.

Levenson JM, O'Riordan KJ, Brown KD, Trinh MA, Molfese DL, Sweatt JD. 2004. Regulation of histone acetylation during memory formation in the hippocampus. J Biol Chem 279: 40545-40559.

MacDonald JL, Roskams AJ. 2008. Histone deacetylases 1 and 2 are expressed at distinct stages of neuro-glial development. Dev Dyn 237: 2256-2267.

McQuown SC, Barrett RM, Matheos DP, Post RJ, Rogge GA, Alenghat T, Mullican SE, Jones S, Rusche JR, Lazar MA, et al. 2011. HDAC3 is a critical negative regulator of long-term memory formation. J Neurosci 31: $764-774$.

Morris MJ, Karra AS, Monteggia LM. 2010. Histone deacetylases govern cellular mechanisms underlying behavioral and synaptic plasticity in the developing and adult brain. Behav Pharmacol 21: 409-419.

Oike Y, Hata A, Mamiya T, Kaname T, Noda Y, Suzuki M, Yasue H, Nabeshima T, Araki K, Yamamura K. 1999. Truncated CBP protein leads to classical Rubinstein-Taybi syndrome phenotypes in mice:
Implications for a dominant-negative mechanism. Hum Mol Genet 8: $387-396$

Oliveira AM, Hawk JD, Abel T, Havekes R. 2010. Post-training reversible inactivation of the hippocampus enhances novel object recognition memory. Learn Mem 17: 155-160.

Peleg S, Sananbenesi F, Zovoilis A, Burkhardt S, Bahari-Javan S, Agis-Balboa RC, Cota P, Wittnam JL, Gogol-Doering A, Opitz L, et al. 2010. Altered histone acetylation is associated with age-dependent memory impairment in mice. Science 328: 753-756.

Prince HM, Bishton MJ, Harrison SJ. 2009. Clinical studies of histone deacetylase inhibitors. Clin Cancer Res 15: 3958-3969.

Roozendaal B, Hernandez A, Cabrera SM, Hagewoud R, Malvaez M, Stefanko DP, Haettig J, Wood MA. 2010. Membrane-associated glucocorticoid activity is necessary for modulation of long-term memory via chromatin modification. J Neurosci 30: 5037-5046.

Save E, Poucet B, Foreman N, Buhot MC. 1992. Object exploration and reactions to spatial and nonspatial changes in hooded rats following damage to parietal cortex or hippocampal formation. Behav Neurosci 106: $447-456$.

Simonini MV, Camargo LM, Dong E, Maloku E, Veldic M, Costa E, Guidotti A. 2006. The benzamide MS-275 is a potent, long-lasting brain region-selective inhibitor of histone deacetylases. Proc Natl Acad Sci 103: $1587-1592$.

Stefanko DP, Barrett RM, Ly AR, Reolon GK, Wood MA. 2009. Modulation of long-term memory for object recognition via HDAC inhibition. Proc Natl Acad Sci 106: 9447-9452.

Suzuki T, Ando T, Tsuchiya K, Fukazawa N, Saito A, Mariko Y, Yamashita T, Nakanishi O. 1999. Synthesis and histone deacetylase inhibitory activity of new benzamide derivatives. J Med Chem 42: 3001-3003.

Sweatt JD. 2009. Experience-dependent epigenetic modifications in the central nervous system. Biol Psychiatry 65: 191-197.

Vannini A, Volpari C, Filocamo G, Casavola EC, Brunetti M, Renzoni D, Chakravarty P, Paolini C, De Francesco R, Gallinari P, et al. 2004. Crystal structure of a eukaryotic zinc-dependent histone deacetylase, human HDAC8, complexed with a hydroxamic acid inhibitor. Proc Natl Acad Sci 101: $15064-15069$.

Vecsey CG, Hawk JD, Lattal KM, Stein JM, Fabian SA, Attner MA, Cabrera SM, McDonough CB, Brindle PK, Abel T, et al. 2007. Histone deacetylase inhibitors enhance memory and synaptic plasticity via CREB:CBP-dependent transcriptional activation. J Neurosci 27: 6128-6140.

Wood MA, Kaplan MP, Park A, Blanchard EJ, Oliveira AMM, Lombardi TL, Abel T. 2005. Transgenic mice expressing a truncated form of CREB-binding protein (CBP) exhibit deficits in hippocampal synaptic plasticity and memory storage. Learn Mem 12: 111-119.

Wood MA, Attner MA, Oliveira AM, Brindle PK, Abel T. 2006a. A transcription factor-binding domain of the coactivator CBP is essential for long-term memory and the expression of specific target genes. Learn Mem 13: 609-617.

Wood MA, Hawk JD, Abel T. 2006b. Combinatorial chromatin modifications and memory storage: A code for memory? Learn Mem 13: $241-244$.

Wu TY, Hassig C, Wu Y, Ding S, Schultz PG. 2004. Design, synthesis, and activity of HDAC inhibitors with a $\mathrm{N}$-formyl hydroxylamine head group. Bioorg Med Chem Lett 14: 449-453.

Yeh S-H, Lin C-H, Gean P-W. 2004. Acetylation of nuclear factor- $\kappa$ B in rat amygdala improves long-term but not short-term retention of fear memory. Mol Pharmacol 65: 1286-1292.

Received December 2, 2010; accepted in revised form March 13, 2011. 


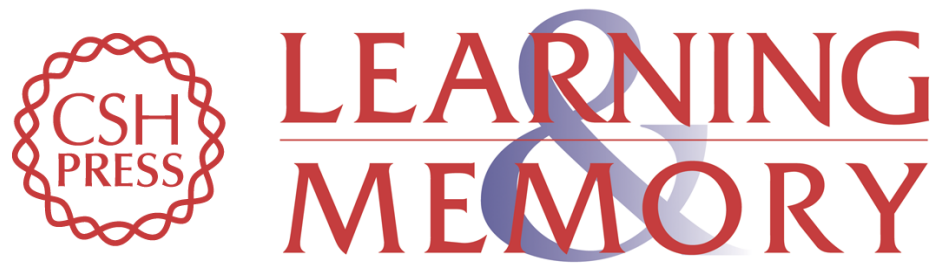

\section{Post-training intrahippocampal inhibition of class I histone deacetylases enhances long-term object-location memory}

Joshua D. Hawk, Cédrick Florian and Ted Abel

Learn. Mem. 2011, 18:

Access the most recent version at doi:10.1101//m.2097411

References This article cites 38 articles, 24 of which can be accessed free at: http://learnmem.cshlp.org/content/18/6/367.full.html\#ref-list-1

License

Email Alerting Receive free email alerts when new articles cite this article - sign up in the box at the Service top right corner of the article or click here. 